\title{
Transcranial Approach versus Endoscopic Transsphenoidal Approach during Midline Suprasellar Meningioma Resection-A Complication and Outcome-Based Study: A Meta-Analysis
}

\author{
Mohan Karki ${ }^{1}$ Chandra Prakash Yadav ${ }^{1}$ Bing Zhao ${ }^{1}$ \\ ${ }^{1}$ Department of Neurosurgery, The Second Affiliated Hospital of \\ Anhui Medical University, Skull Base Tumor Research Center, Anhui \\ Medical University, Anhui Province, China \\ Indian J Neurosurg 2016;5:145-158. \begin{abstract}
Neurosurgery, The Second Affiliated Hospital of Anhui Medical University, Skull Base Tumor Research Center, Anhui Medical University, 678 Fu Road, Hefei, Anhui Province 230601, China
\end{abstract} \\ Address for correspondence Prof. Bing Zhao, MD, Department of \\ (e-mail: -zhaopumcmd@yeah.net).
}

\begin{abstract}
Background and Purpose The choice of surgical approach for the removal of midline suprasellar meningiomas (MSM) has long remained inconclusive among neurosurgeons. While some neurosurgeons prefer transcranial approach (TCA), others favor the use of endoscopic transsphenoidal approach (ETSA). Retrospectively, we assessed the effectiveness of TCA and ETSA on the basis of postoperative outcome and complications to inform future clinical decision making on MSMs.

Materials and Methods A retrospective systematic review and meta-analysis was performed on published case series in PubMed from the year 2000 to 2014 . Demographic data, clinical variables, and outcome measures of patients who had their MSMs surgically removed via TCA or ETSA were subjected to rigorous statistical analysis.

Results There were 48 studies with 1,466 patients who underwent TCA (32 studies) and ETSA (16 studies). TCA had a statistically significant rate of tumor recurrence

Keywords

- midline suprasellar meningiomas

- transcranial and endoscopic transsphenoidal approach

- outcomes and metaanalysis ( $p=0.02$; odds ratio [OR], 1.8; 95\% confidence interval [CI], 1.1-6.39) while ETSA had a high rate of CSF leakage ( $p=0.04 ; \mathrm{OR}, 25 ; 95 \% \mathrm{Cl}, 1.78-11.56)$. Both TCA and ETSA did not improve visual recovery and gross total resection, but only minimally influenced total clinical outcome.

Conclusion Put together, ETSA and TCA did not improve CSF leakage rate and tumor recurrence respectively, but in the absence of a surgical approach that could maximize the advantages of both TCA and ETSA, it is advisable that neurosurgeons take an informed clinical decision reflective of patient peculiar clinical presentations as well as risk/benefit profile of surgical technique.
\end{abstract}

\section{Introduction}

Approximately, 5 to $10 \%$ of all intracranial meningiomas are midline suprasellar meningiomas (MSMs) ${ }^{1}$ that normally originate from tuberculum sellae (TS), diaphragm sellae (DS), and planum sphenoidale (PS). ${ }^{2-9}$ MSMs are benign, slow growing, encapsulated, and normally attached to a part of the dura, falx, or tentorium. ${ }^{2,10}$ MSMs exhibit complex symptoms such as adhering to vascular walls or completely engulfing them, however, they typically do not invade blood received

April 21, 2016

accepted

June 1, 2016

published online

October 25, 2016
DOI http://dx.doi.org/

10.1055/s-0036-1588035. ISSN 2277-954X. (c) 2016 Neurological Surgeons' Society of India

License terms

(c) $(1) \$$ 
vessels. In view of the delicate anatomic location and proximity of MSMs to neurovascular structures (internal carotid artery and its branches, mainly anterior cerebral artery and anterior communicating artery, optic apparatus) and the pituitary gland, ${ }^{11}$ they represent a major problem for surgical removal by neurosurgeons. In most cases, visual disturbances secondary to displaced optic apparatus is the main clinical presentation. ${ }^{12-16}$ A successful surgical removal of MSM is normally characterized by removal of the tumor along with surrounding dura and associated hyperostotic bone while preserving vision. Postoperation visual recovery or preservation of vision is the gold standard for assessing surgical approaches for MSMs., 13,17,18

Two most commonly used surgical approaches for MSM are the traditional transcranial approach (TCA) or microscopic/ modern endoscopic transsphenoidal approach (ETSA). Neurosurgeons are divided when it comes to the choice of surgical approach for the removal of MSMs. Although some studies have investigated the choice of TCA and TSA for surgical removal of suprasellar meningiomas on the basis of some postoperative outcome measures including visual improvement, cerebrospinal fluid (CSF) leakage, tumor recurrence, and gross total resection (GTR), ${ }^{19-21}$ yet the choice problem remains unsolved. This problem has been attributed to many factors including limited studies on the topic, methodological heterogeneity, and small patient numbers as well as biased reporting. For example, case series on meningiomas removed by ETSA series were shown to be small lesions, ${ }^{22}$ this gives biased impression of ETSA compared with TCA.

To contribute, the present systematic review retrospectively analyzed published case series on MSMs independently removed by TCA or ETSA. Importantly, this review subjected the data captured in these published studies to rigorous metaanalysis as a means to provide rationale for the choice of surgical techniques for MSM management.

\section{Methods}

\section{Search Methodology}

We searched for data on case series published in PubMed from the year 2000 to 2014. Regarding study design, 32 articles were under transcranial group $5-9,11,13-16,18-21,23-40$ and 16 articles were under endoscopic group. ${ }^{19-22,41-52}$ The following search terms: meningioma, tuberculum sellae, diaphragm sellae, planum sphenoidale, transcranial, resection, and outcomes were used either singly or in combination. The following approaches: frontotemporal/pterional, unilateral subfrontal, bilateral subfrontal, supraorbital, and interhemispheric were collectively designated as TCA. For the purpose of comparison, similar searches were performed using the terms; endoscopy, endonasal, transsphenoidal, midline suprasellar, tuberculum sellae, diaphragm sellae, and planum sphenoidale meningiomas. Likewise, only endoscope-assisted or microscope- and endoscopic-assisted approaches were collectively designated as ETSA. Data reported in aggregated form were included to report overall pooled rates. The assessment of efficacy of the procedures was based on surgical outcomes: visual improvement, GTR, and perioperative complications. There was disparity on visual functioning among the case series, mostly between formal visual field testing and subjective patient assessment method; however, both were used as a means to assess visual field in this study. Also, strength of evidence score (SOES) was designed based on a criteria (-Table $\mathbf{1}$ ).

\section{Inclusion and Exclusion Criteria}

Only patients with tumor specifically located in the TS, DS, or PS were included in this study. The studies were reviewed and observations were made regarding study design, methodology, and patient characteristics (-Table 2).The cases for each study were extracted and the cohorts assessed based on preoperative clinical features (visual deficits, headache, and endocrinopathy) and postoperative outcomes (visual function, GTR, occurrence of CSF leakage, and tumor recurrence). Similarly, morbidity assessment was based on frequency of infection (pneumonia, meningitis, and wound/bone flap infection), seizure, hemorrhage, visual worsening, endocrinopathy, and anosmia. Information on mortality, if available, was captured. Age was categorized into $\leq 50$ or $>50$ years. Tumor size was categorized into $\leq 2.4$ or $>2.4 \mathrm{~cm}$. Also, duration of symptoms was categorized into $\leq 12$ or $>12$ months. The $p$-values $\leq 0.05$ were considered statistically significant in all analysis. Duplication of patients was eliminated in case series where multiple papers were published by the same authors or the same institution. In such situations, only reports with the largest sample size and relevant data were selected.

Table 1 Strength of evidence scoring (SOES) system demonstrating the assignment of scores based on visual assessment, demographic variables (sex, mean age, size, and volume of tumor, and volume of tumor resection) in patients that were operated for MSM

\begin{tabular}{|l|l|}
\hline Included variable & SOES \\
\hline $\begin{array}{l}10 \text { or more patients } \\
\text { Postoperative vision assessment } \\
\text { Renvisual complication } \\
\text { extent of resection }\end{array}$ & 1 \\
\hline $\begin{array}{l}10 \text { or more patients } \\
\text { Postoperative vision assessment OR } \\
\text { Nonvisual complication } \\
\text { Reported age, sex, size, or volume or } \\
\text { extent of resection }\end{array}$ & \\
\hline $\begin{array}{l}10 \text { or more patients } \\
\text { Postoperative vision assessment OR } \\
\text { Nonvisual complication OR } \\
2 \text { of } 3 \text { (reported age sex, size, or } \\
\text { volume or extent of resection) }\end{array}$ & 3 \\
\hline $\begin{array}{l}\text { Either } 10 \text { or more patients OR } \\
\text { Postoperative vision assessment OR } \\
\text { Nonvisual complication OR } \\
1 \text { of } 3 \text { (reported age, sex, size, or } \\
\text { volume or extent of resection) }\end{array}$ & \\
\hline
\end{tabular}

Abbreviation: MSM, midline suprasellar meningioma; OR, odds ratio. 


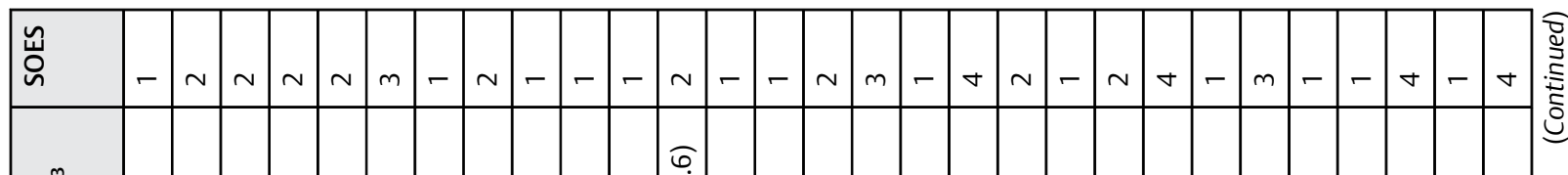

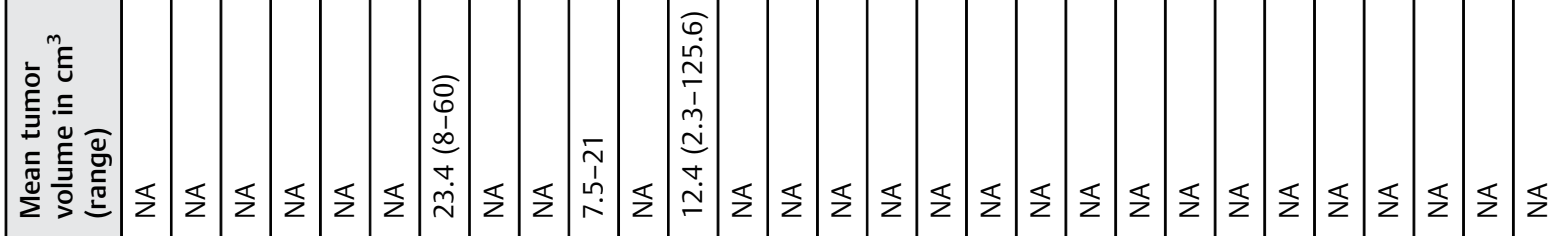

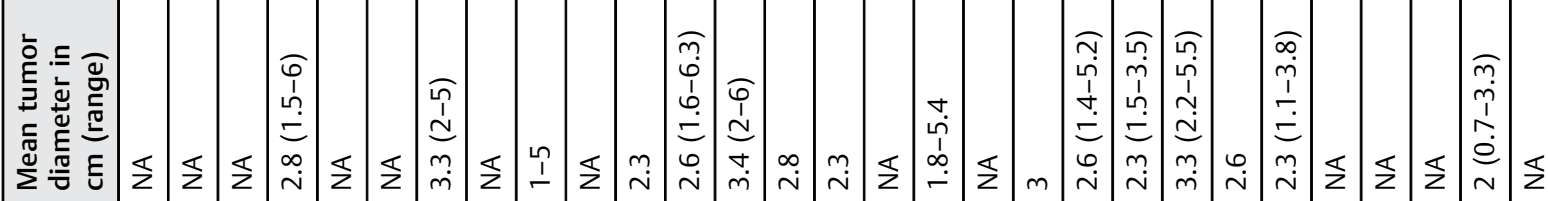

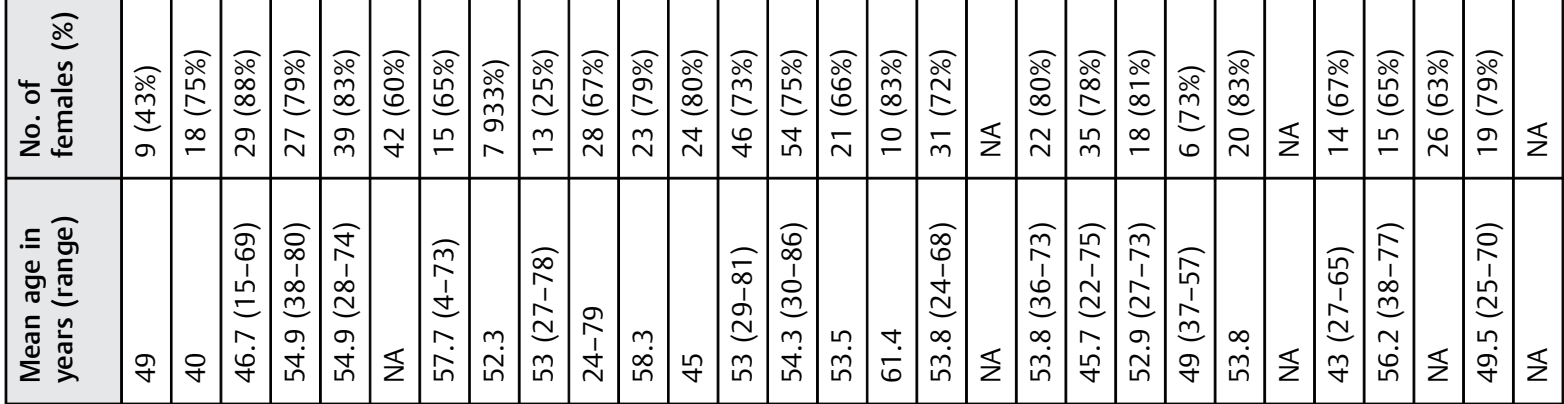

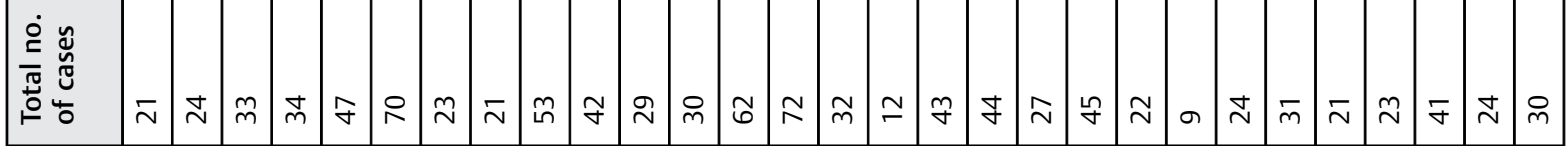

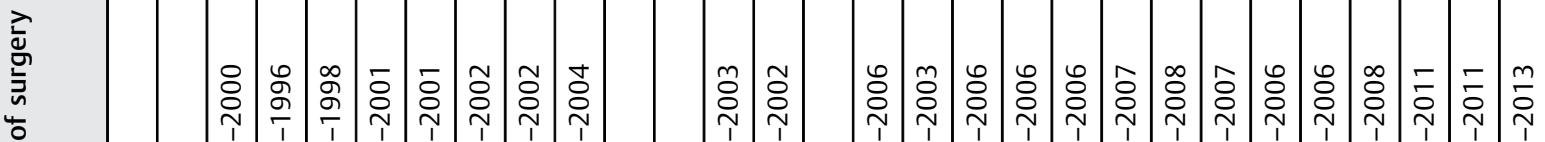

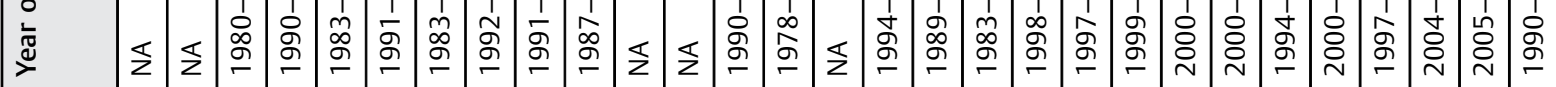

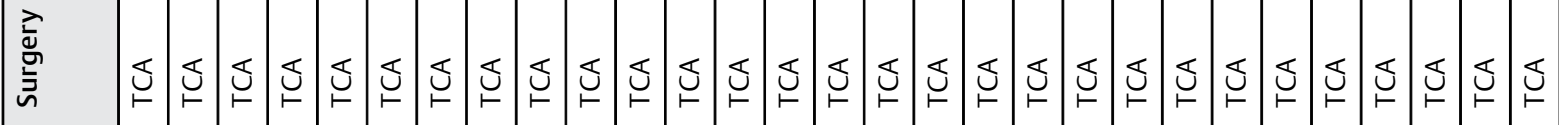

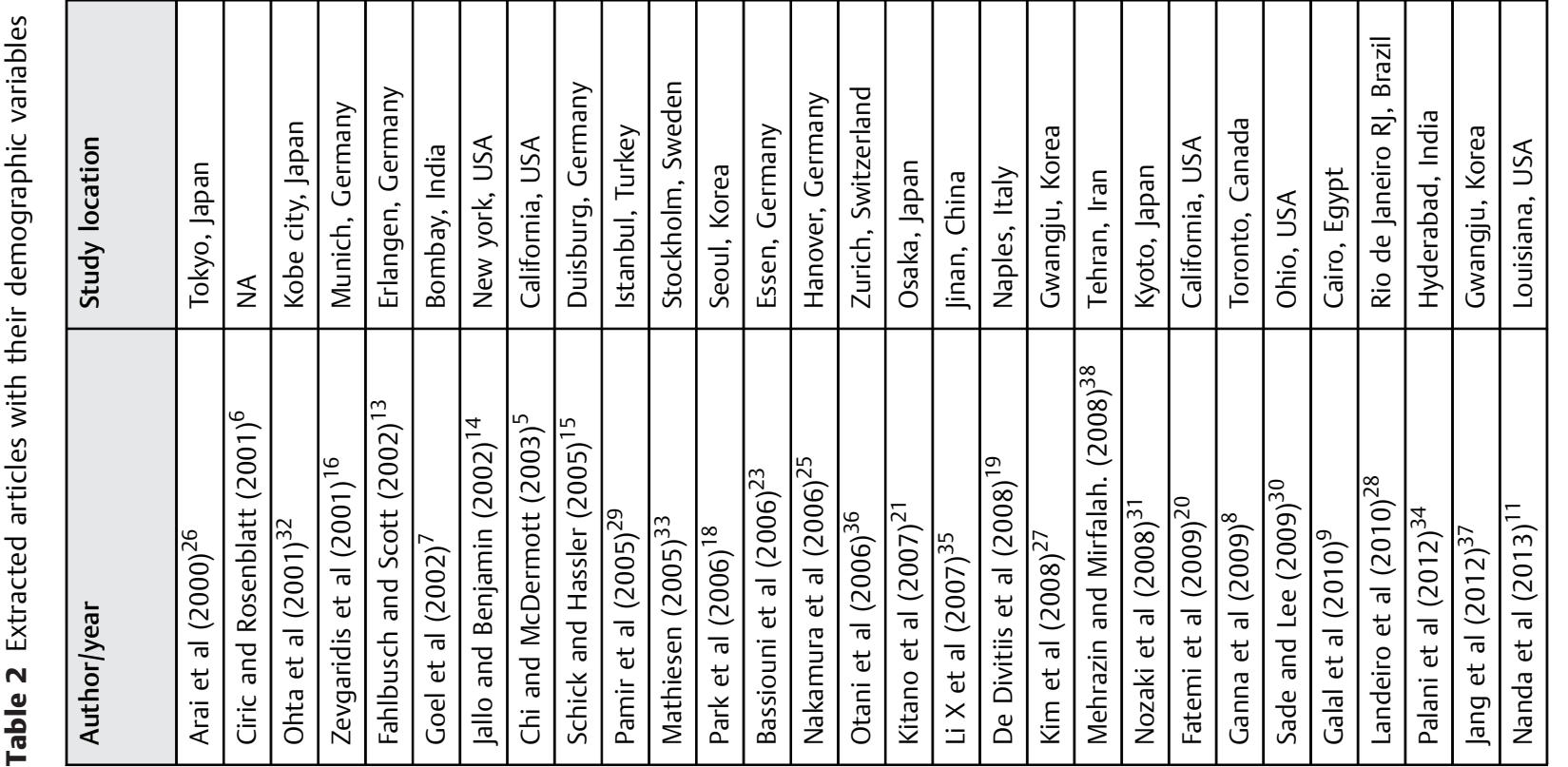




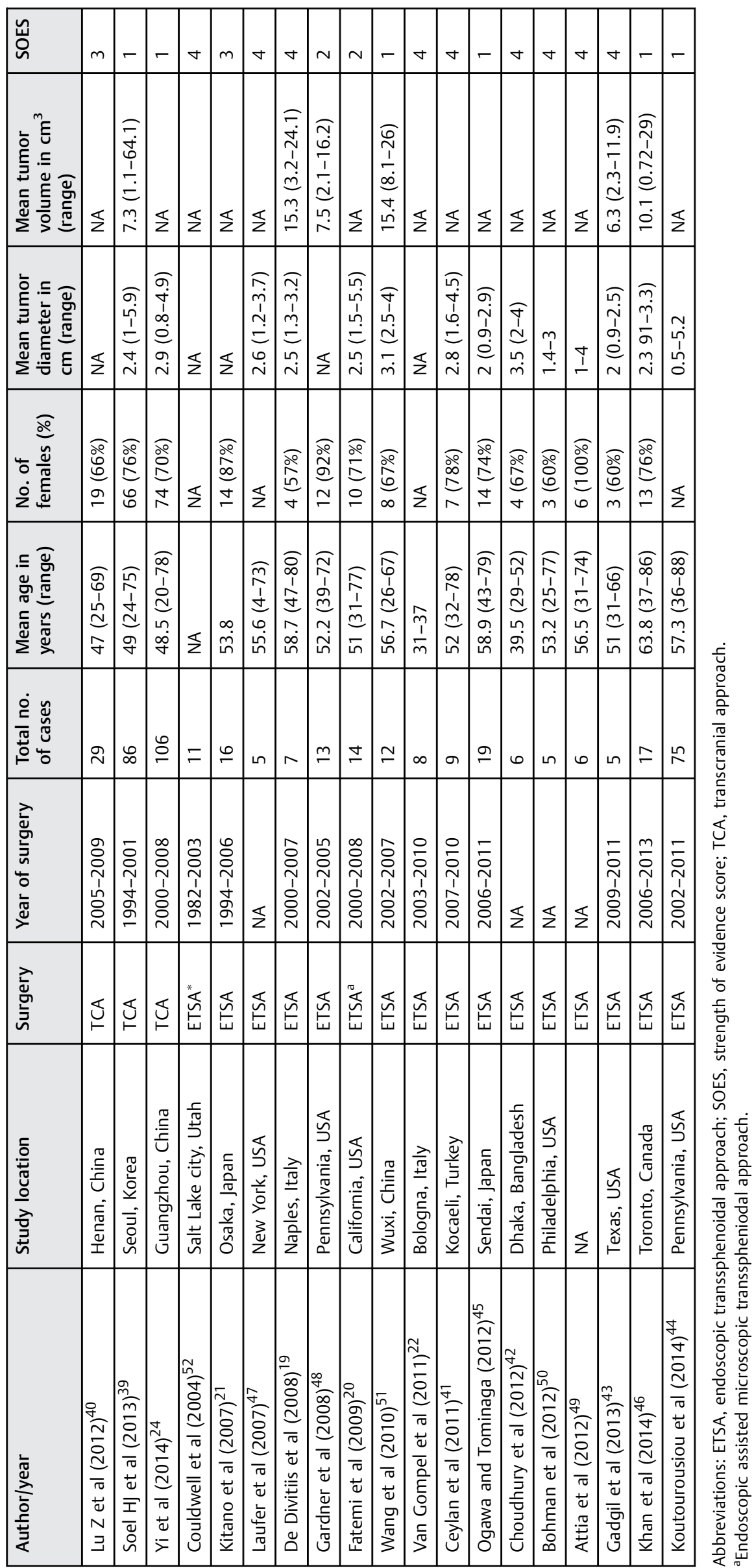




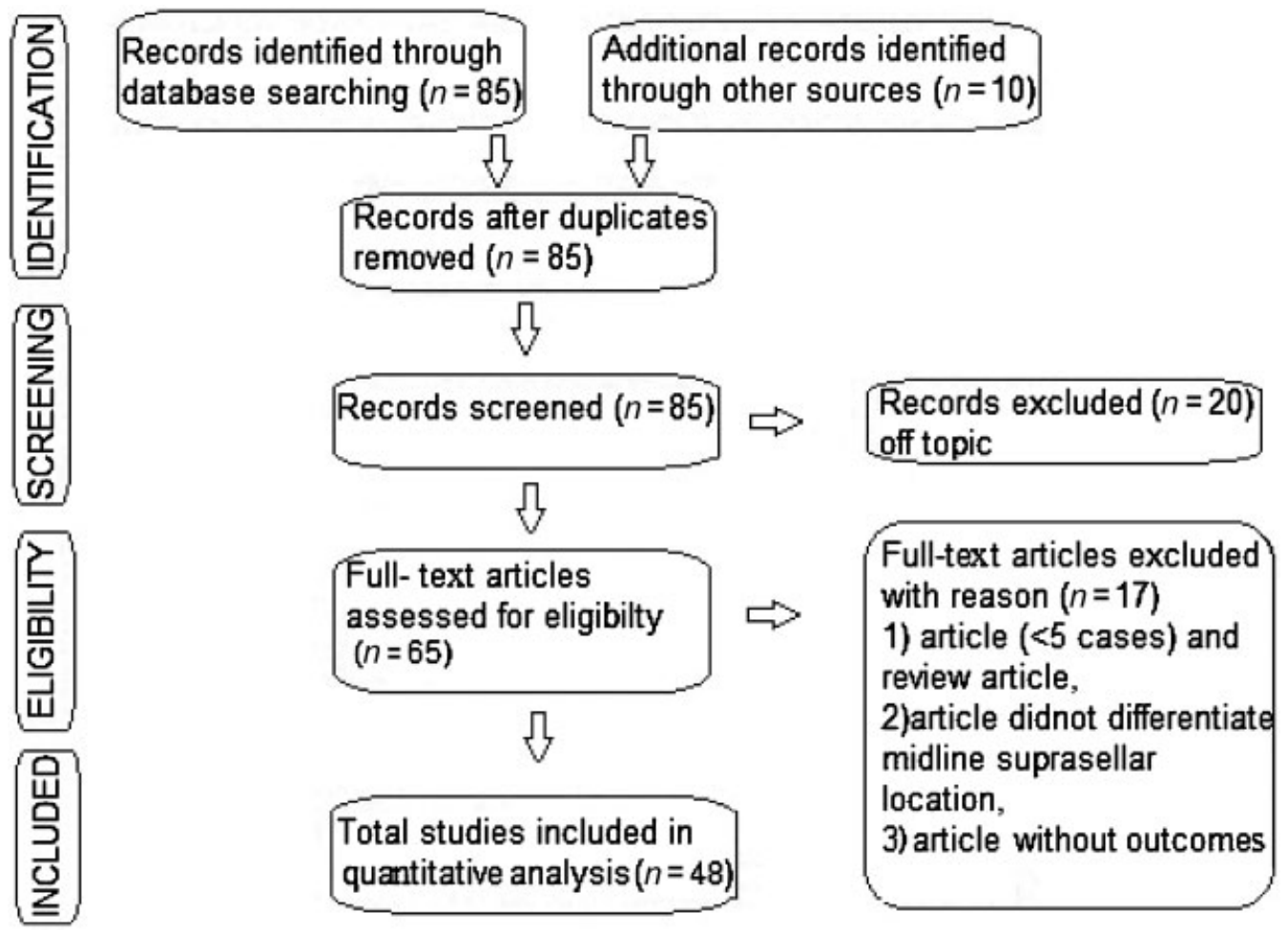

Fig. 1 Flow diagram showing systemic analysis process (PRISMA flow diagram).

\section{Overcoming Bias}

Only disaggregated data were included for analysis of predictive factors. An assessment of bias was made only on the outcome measures but not on individual studies because only case series and case reports were included in this study. Publication bias was assessed by using funnel plots on natural logarithmic scale followed by Egger's linear regression. The study design is presented in a flow diagram (-Fig. 1).

\section{Statistical Analysis}

Statistical analysis was done by using SPSS software (version 17.0; Chicago, Illinois, United States) and Stata (version 11.0; college station, Texas, United States). Meta-analysis on calculated pooled proportion of individual outcomes for TCA and ETSA groups was independently performed. The disaggregated individual patient data from studies were summarized for the purpose of statistical analysis. Results were designated as proportions (\%) and 95\% confidence intervals $(\mathrm{CI})$ were resolved using the exact binomial method. Heterogeneity was estimated using Cochran Q statistic, and random effect models were used to correlate the heterogeneity between proportions as previously described $^{53-56}$.Each individual study was weighted by using the inverse variance method at 95\% CIs and each pooled effect size proportion was estimated by using inverse $\mathrm{Zr}$ transformation of the proportion generated from random effects model. ${ }^{53-56}$ Between the groups, hypothesis testing was performed on calculated $95 \% \mathrm{CIs}$ of the pooled proportions. Odds ratio (OR) was calculated by dividing the pooled TCA proportion by the pooled ETSA proportion for the specific outcome of interest.

\section{Results}

\section{Preoperative Assessments}

Out of a total of 1,466 patients who were admitted for MSM surgery involving TCA and ETSA, females were in the majority for both approaches (-Table 3 ). There was a significant difference between the two approaches with regard to mean patient age, visual impairment, mean length of follow-up, and headache, but not tumor size and volume (-Table 3).

\section{Postoperative Assessment of Outcome Measures}

For both approaches, worsening of visual impairment, visual improvement, and GTR numerically differed; however, the differences were statistically insignificant except in the case of CSF leakage (-Table 4, - Fig. 2, 3 and 4).Comparing various overall perioperative complications with respect to the two approaches, it was found that both procedures had association with some complications (seizure, CSF leakage, hemorrhage, and mortality), while there was no association for others (visual worse, infections, endocrinopathy, and anosmia) (-Fig. 6). TCA was associated with decreased CSF leakage but increased recurrence rate, while ETSA showed decreased recurrence rate but increased CSF leakage, and the differences between the two approaches were statistically significant (-Table 4).

\section{Publication Bias for Pooled Proportion}

Finally, we investigated publication bias of case series for significant and nonsignificant pooled proportions with Begg's funnel plot, and it showed similar asymmetry. Only 
Table 3 Comparison of clinical characteristics of patients who underwent TCA and ETSA for resection of midline suprasellar meningiomas, from studies in which patient data were reported in disaggregated form

\begin{tabular}{|c|c|c|c|c|c|}
\hline Preoperative variables & No. of studies & TCA & No. of studies & ETSA & $p$-Value \\
\hline \multicolumn{6}{|l|}{ Age $(y)$} \\
\hline$<50$ y $(\%)$ & 11 & $428(44)$ & 1 & $6(3)$ & 0.001 \\
\hline$>50$ y $(\%)$ & 15 & $524(55)$ & 13 & $203(97)$ & \\
\hline \multicolumn{6}{|l|}{ Sex } \\
\hline Male (\%) & 29 & $336(30)$ & 12 & $39(28)$ & 0.776 \\
\hline Female (\%) & 29 & $782(70)$ & 12 & $98(71)$ & \\
\hline \multicolumn{6}{|l|}{ Presenting symptoms } \\
\hline Headache (\%) & 12 & $244(42)$ & 10 & $30(20)$ & 0.001 \\
\hline Endocrine abnormalities (\%) & 7 & $34(13)$ & 4 & $10(9)$ & 0.362 \\
\hline Preoperative visual deficits (\%) & 31 & $1,075(91)$ & 15 & $175(81)$ & 0.001 \\
\hline \multicolumn{6}{|l|}{ Tumor characteristics } \\
\hline Mean tumor diameter, cm (range) & 18 & $3(0.8-63)$ & 12 & $2.5(0.5-5.9)$ & 0.135 \\
\hline Mean tumor volume, $\mathrm{cm}^{3}$ (range) & 4 & $14.3(1.1-125.6)$ & 5 & $11(0.7-29)$ & 0.072 \\
\hline Optic canal involvement (\%) & 9 & $149(36)$ & 1 & $20(26)$ & 0.114 \\
\hline Major vascular encasement (\%) & 8 & $135(40)$ & 4 & $59(47)$ & 0.218 \\
\hline Mean follow-up (mo, range) & 27 & $53(3-192)$ & 12 & $19(1-98)$ & 0.002 \\
\hline Mean tumor volume, $\mathrm{cm}^{3}$ (range) & 4 & $14.3(1.1-125.6)$ & 5 & $11(0.7-29)$ & 0.072 \\
\hline
\end{tabular}

Abbreviations: ETSA, endoscopic transsphenoidal approach; TCA, transcranial approach.

Funnel plot with respect to CSF leakage is shown (-Fig. 5) and it was a nonsignificant plot $(p>0.05)$. From Egger's test performed on the publications used in this study, there was no bias with specific respect to visual improvement, GTR, and CSF leakage (-Table 5 ).

\section{Discussion}

\section{Background}

Complete removal of MSM via the TCA, first described by Stirling and Edin in $1897,{ }^{57}$ was performed by Cushing and Eisenhardt in

Table 4 Comparison of surgical outcomes after resection of midline suprasellar meningioma (MSM) between TCA and ETSA groups

\begin{tabular}{|c|c|c|c|}
\hline Variables & Proportion & OR; $95 \% \mathrm{Cl}$ & $p$-value \\
\hline \multicolumn{4}{|l|}{ GTR } \\
\hline TCA & 0.80 & $1.3 ; 0.74-7.68$ & 0.43 \\
\hline ETSA & 0.83 & & \\
\hline \multicolumn{4}{|c|}{ Visual improved } \\
\hline TCA & 0.71 & $1.2 ; 0.25-8.92$ & 0.26 \\
\hline ETSA & 0.70 & & \\
\hline \multicolumn{4}{|l|}{ CSF leak } \\
\hline TCA & 0.08 & $2.5 ; 1.78-11.56$ & 0.04 \\
\hline ETSA & 0.17 & & \\
\hline \multicolumn{4}{|c|}{ Visual worse } \\
\hline TCA & 0.18 & $1.6 ; 0.43-6.11$ & 0.12 \\
\hline ETSA & 0.15 & & \\
\hline \multicolumn{4}{|c|}{ Tumor recurrence } \\
\hline TCA & 0.07 & $1.8 ; 1.1-6.39$ & 0.02 \\
\hline ETSA & 0.05 & & \\
\hline
\end{tabular}

Abbreviations: Cl, confidence interval; CSF, cerebrospinal fluid; ETSA, endoscopic transsphenoidal approach; GTR, gross total resection; OR, odds ratio; TCA, transcranial approach. 
TCA versus ETSA during MSM Karki et al. 151

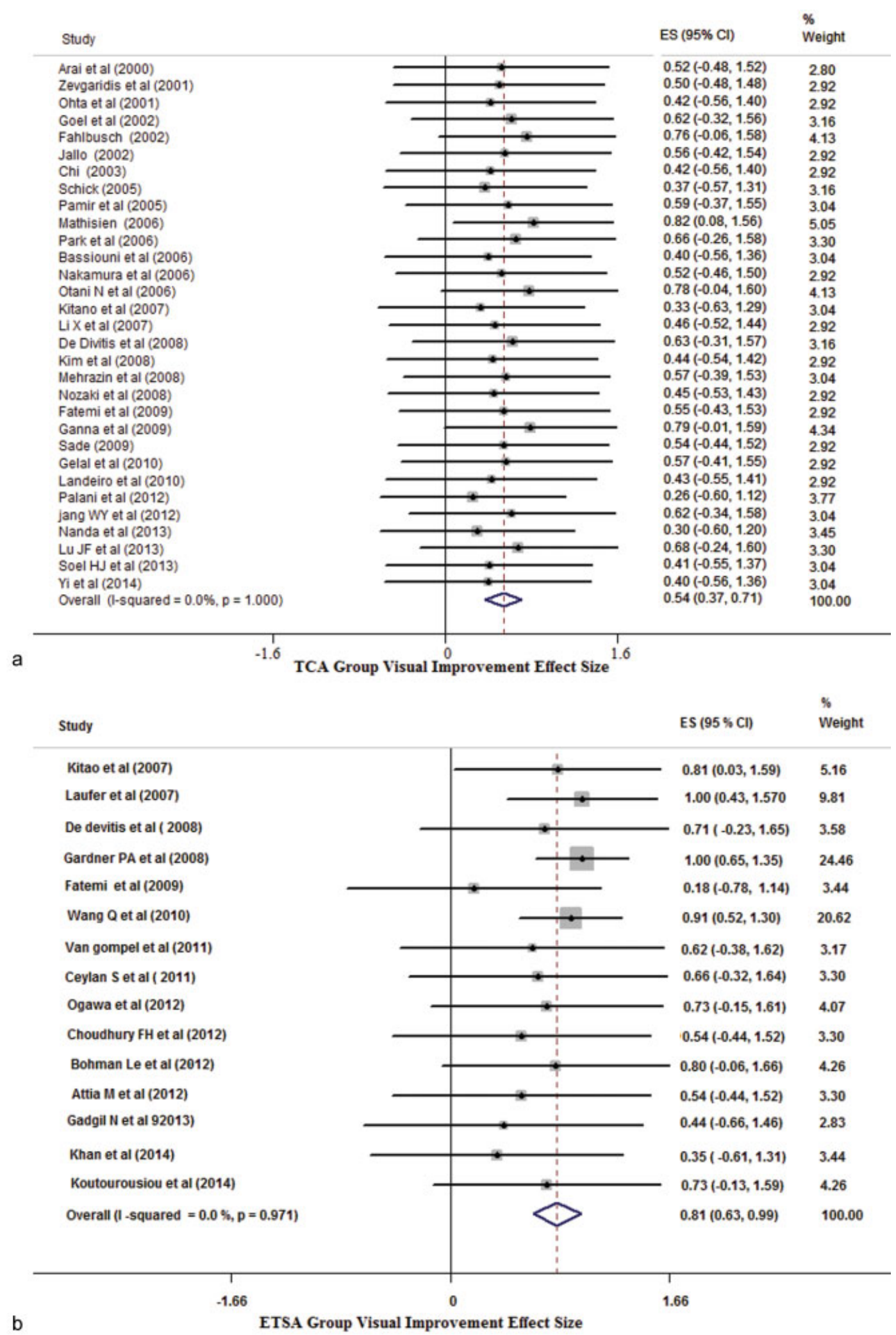

Fig. 2 It demonstrates comparison between transcranial and endoscopic transsphenoidal approach with respect to postoperative visual improvement. Forest plot demonstrates the $95 \%$ confidence intervals and percentiles weights associated with the individual and combined study groups for (a) transcranial approach group and (b) endoscopic transsphenoidal approach group. 


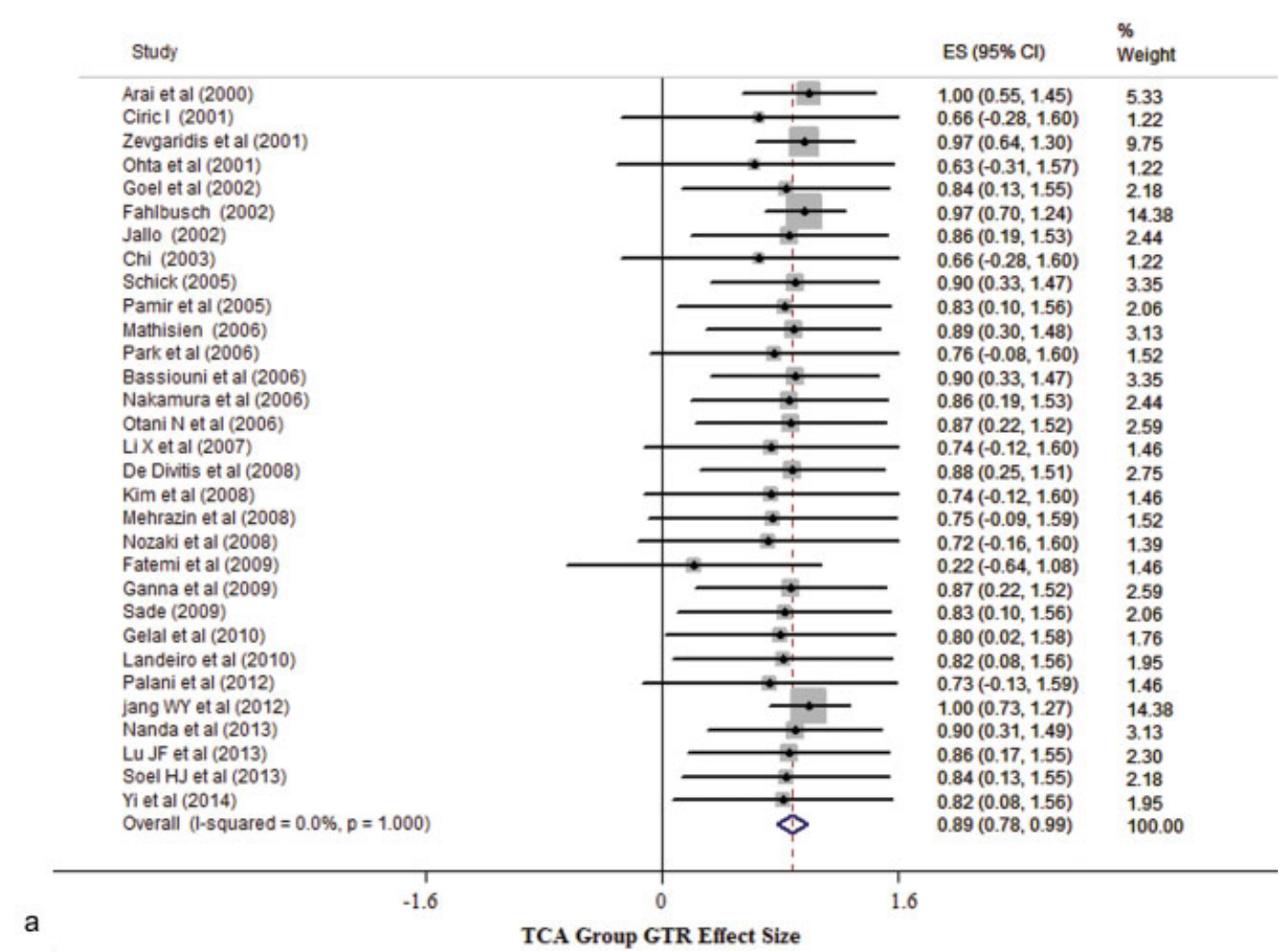

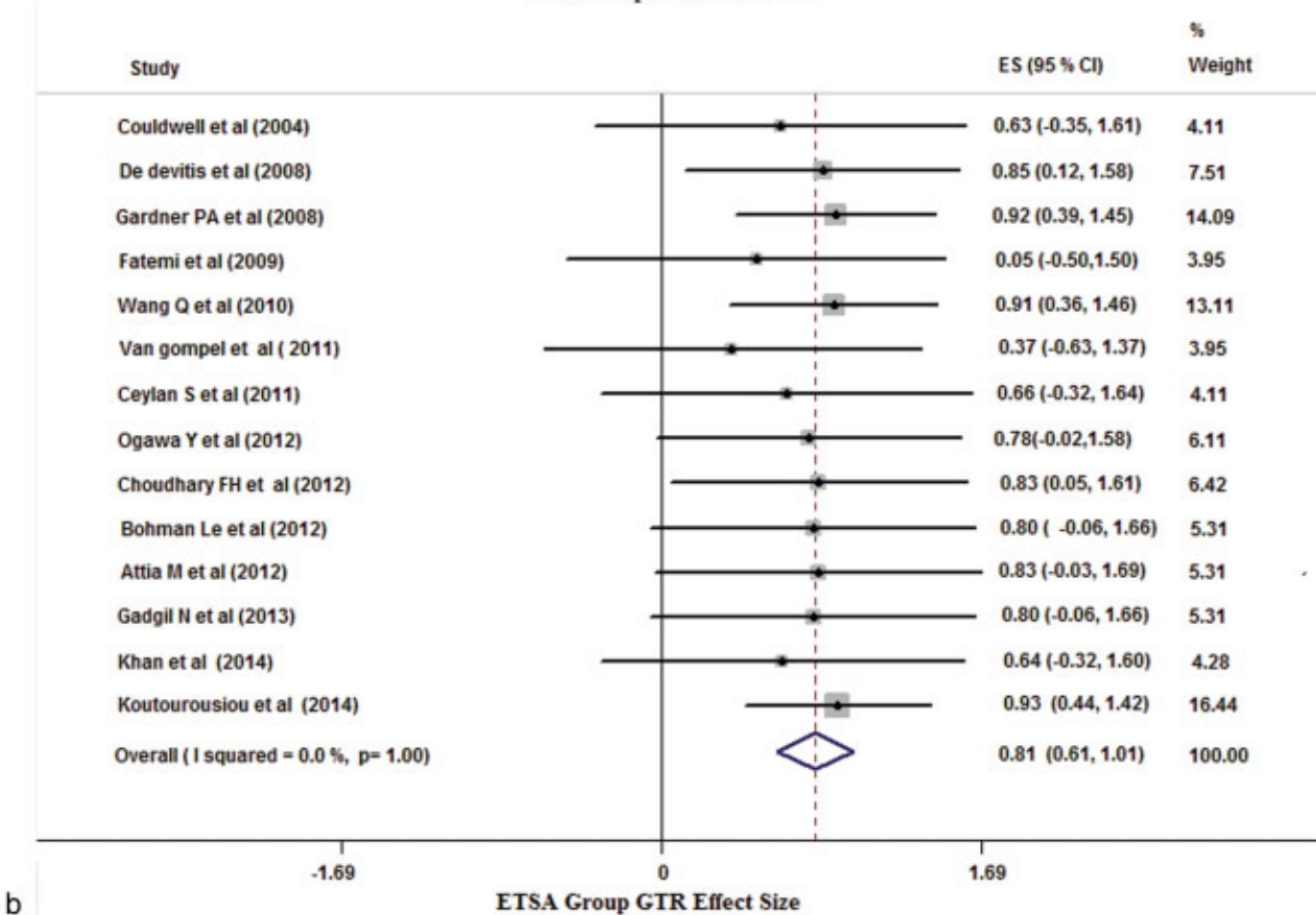

Fig. 3 It demonstrates comparison between transcranial and endoscopic transsphenoidal approach with respect to gross total resection. Forest plot demonstrates the $95 \%$ confidence intervals and percentiles weights associated with the individual and combined study groups for (a) transcranial approach group and (b) endoscopic transsphenoidal approach group.

$1916 .^{58}$ Since then, MSMs have been removed by different transcranial approaches that include: frontolateral, frontotemporal/pterional, orbitopterional/orbitozygomatic, unilateral subfrontal, bilateral subfrontal, interhemispheric, supraorbital, and pterional. $7,13,14,25,30-33,59,60$ With time, the complications, risks, and associated morbidities with TCA gave rise to TSA that was devoid of the previous risks. TSA was introduced by Herman Schloffer, who in 1907 resected a pituitary tumor via TSA. ${ }^{61}$ TSA was found to be effective and safer for suprasellar meningiomas that were predominantly 


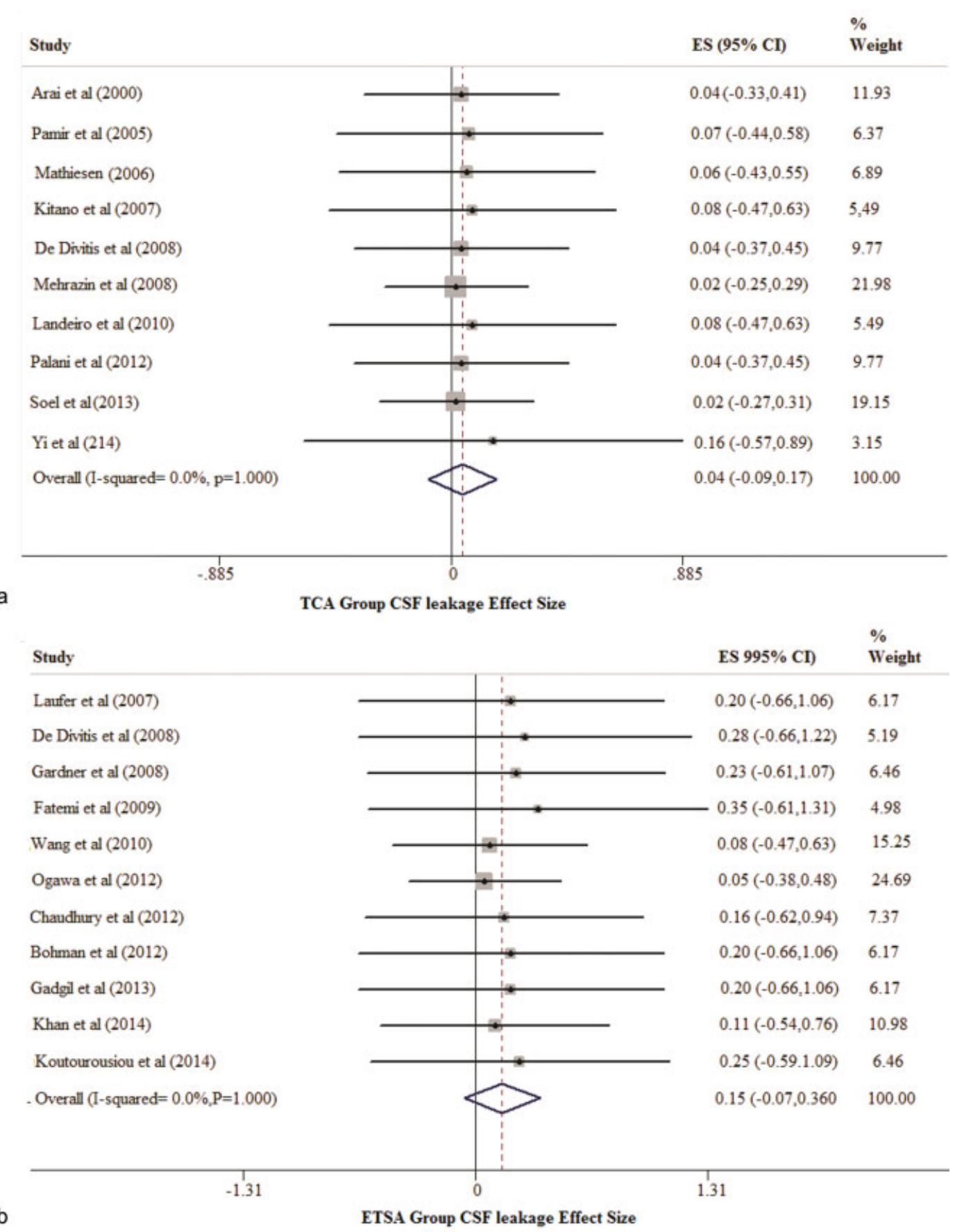

Fig. 4 It demonstrates comparison between transcranial and endoscopic transsphenoidal approach with respect to cerebrospinal fluid leakage. Forest plot demonstrates the $95 \%$ confidence intervals and percentiles weights associated with the individual and combined study groups for (a) transcranial approach group and (b) endoscopic transsphenoidal approach group.

located in the midline ${ }^{17,47,62-66}$ though its study-based advantages and disadvantages need affirmation. ${ }^{13,25,52,67}$ Even though TSA has refined with evolution of microscope-based ${ }^{52,68}$ or currently by endoscope-based techniques, ${ }^{21,47,69-71}$ there still remains the most common problem of CSF leakage. Similarly, to limit this CSF leakage during ETSA, varieties of closure methods like: fat and fascial graft, ${ }^{72}$ fat and synthetic dural substitute, ${ }^{51}$ mixture (fascial graft, methacrylate, mucoperichondrium, and fibrin glue), ${ }^{73}$ mixed (fascia lata and Nissel or DuraSeal), ${ }^{47}$ or mixed (fascial graft and nasoseptal flap) ${ }^{46}$ for dural reconstruction have been proposed. Among these closure methods, a study done by de Divitiis ${ }^{19}$ has reported a higher (29\%) rate of CSF leakage that specifically utilized a multilayer closure involving collagen matrix, dural substitute, a reabsorbable plate, and fibrin sealant. Various reconstruction techniques during the TCA have been suggested to prevent postoperative CSF leakage that occur mainly in the frontal sinus $^{74}$ and resultant meningitis, including the use of pericranial flap with or without adipose tissue being the most popular one. ${ }^{6,75}$ Progressively, however, with the evolution of vascularized nasoseptal flap reconstruction technique, the CSF leakage rate has dramatically decreased to $16 \%$ with a $p$-value 


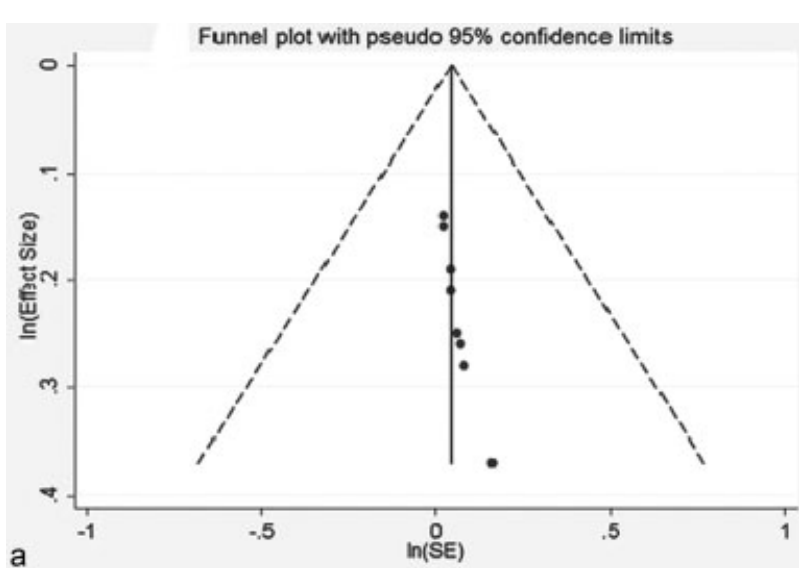

Funnel plot with pseudo $95 \%$ confidence limits

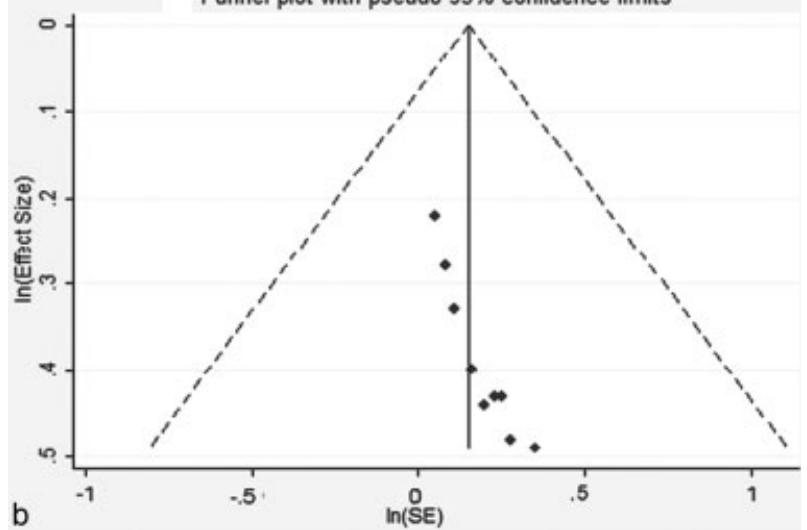

Fig. 5 Begg's funnel plot for publication bias in cerebrospinal fluid leak for both (a) transcranial approach and (b) endoscopic transsphenoidal approach. Points indicate the effect size (pointed as a proportion) included in meta-analysis plotted against the calculated standard error on a natural logarithm scale, dashed line represents 95\% confidence interval,

approaching $<0.0001 .^{76,77}$ Whatever the modification be made with procedures, reconstruction performed with a dural or institution of a newer vascularized nasoseptal sealing technique, higher rate of CSF leakage still persists with ETSA.

\section{Evolution of Microscopic and Endoscopic Transsphenoidal Approach}

ETSA is an endoscopic-guided MSM removal procedure that delivers good illumination, wide panoramic view of the surgical target especially between the PS and clival recess.
Some of the studies performed on ETSA have reported complete resection of tumor in $88 \%$ patients, with visual improvement in $87 \%$ and visual worsening in $6 \%{ }^{78}$ while Couldwell et $\mathrm{al}^{52}$ have reported complete resection in $64 \%$ patients with tuberculum sellae meningioma and visual worsening in $9 \%$ with microscope-based TSA. Similar results have also been documented by Fatemi et al with complete resection in $50 \%$ patients, near total resection in $21 \%$ patients, with visual improvement in $82 \%$ and visual worsening in $7 \% .^{20}$ However, access through a small aperture of nasal speculum in the microscope-based TSA approach alone had drawbacks by the limited exposure of operative corridor, field of view of surgical target, and surgical freedom of instrument maneuverability. Moreover, studies performed by Kaptain et al, Dusick et al, Cook et al, and Couldwell et al comparing the superiority among these procedures, have revealed that rather than individual microscope-based TSA or ETSA, combination of both procedures were found to be the superior approach due to the wide degree of visual freedom it provided during exploration and removal of the tumor. ${ }^{17,52,62,63}$

\section{Procedures Related Advantages and Disadvantages of Transcranial Approach and Endoscopic Transsphenoidal Approach}

Both of the procedures have their own advantages over each other but the specific choices in treatment of MSM have been on an ad hoc basis. The important advantages of the TCA have been: surgeon's familiarity with traditional approach, direct microscopic visualization of the tumor, early identification of adjacent neurovascular structure, early decompression of the optic nerve via anterior clinoidectomy, increased range of instrument maneuverability (surgical freedom), better control of vascular structures, and ability to address tumor that extends superiorly or laterally on the optic nerve. ${ }^{72}$ TCA, however, has some disadvantages like: easily visible scar, longer recovery time, risk of injury to brain tissue caused by frontal lobe retraction, difficulty in removing tumors located medial to ipsilateral carotid artery/optic nerve, ${ }^{19,72}$ and the incidences of increased blood losses. Similarly, ETSA has been superior at early devascularization of the main feeding arteries, ${ }^{19}$ early decompression of the medial side of optic nerve by unflooring the optic canal, ${ }^{21}$ visualizing the lower plane of the optic chiasma, ${ }^{9,51,52,72}$ and providing better

Table 5 Summary of results of publication bias

\begin{tabular}{|l|l|l|l|l|}
\hline \multirow{2}{*}{ Approaches } & \multirow{2}{*}{ Variables } & \multicolumn{2}{|c|}{ Publication bias ( $p$-value) } & \multirow{2}{*}{ Number of studies } \\
\cline { 3 - 5 } & & Begg's & Egger's \\
\hline \multirow{5}{*}{ TCA } & Visual improvement & 0.07 & 0.12 & 31 \\
\cline { 2 - 5 } & Gross total resection & 0.23 & 0.27 & 31 \\
\cline { 2 - 5 } & CSF leak & 0.36 & 0.41 & 10 \\
\hline \multirow{3}{*}{ ETSA } & Visual improvement & 0.22 & 0.18 & 15 \\
\cline { 2 - 5 } & Gross total resection & $p=0.59$ & $p=0.45$ & 14 \\
\cline { 2 - 5 } & CSF leak & $p=0.09$ & $p=0.11$ & 12 \\
\hline
\end{tabular}

Abbreviations: CSF, cerebrospinal fluid; ETSA, endoscopic transsphenoidal approach; TCA, transcranial approach. 


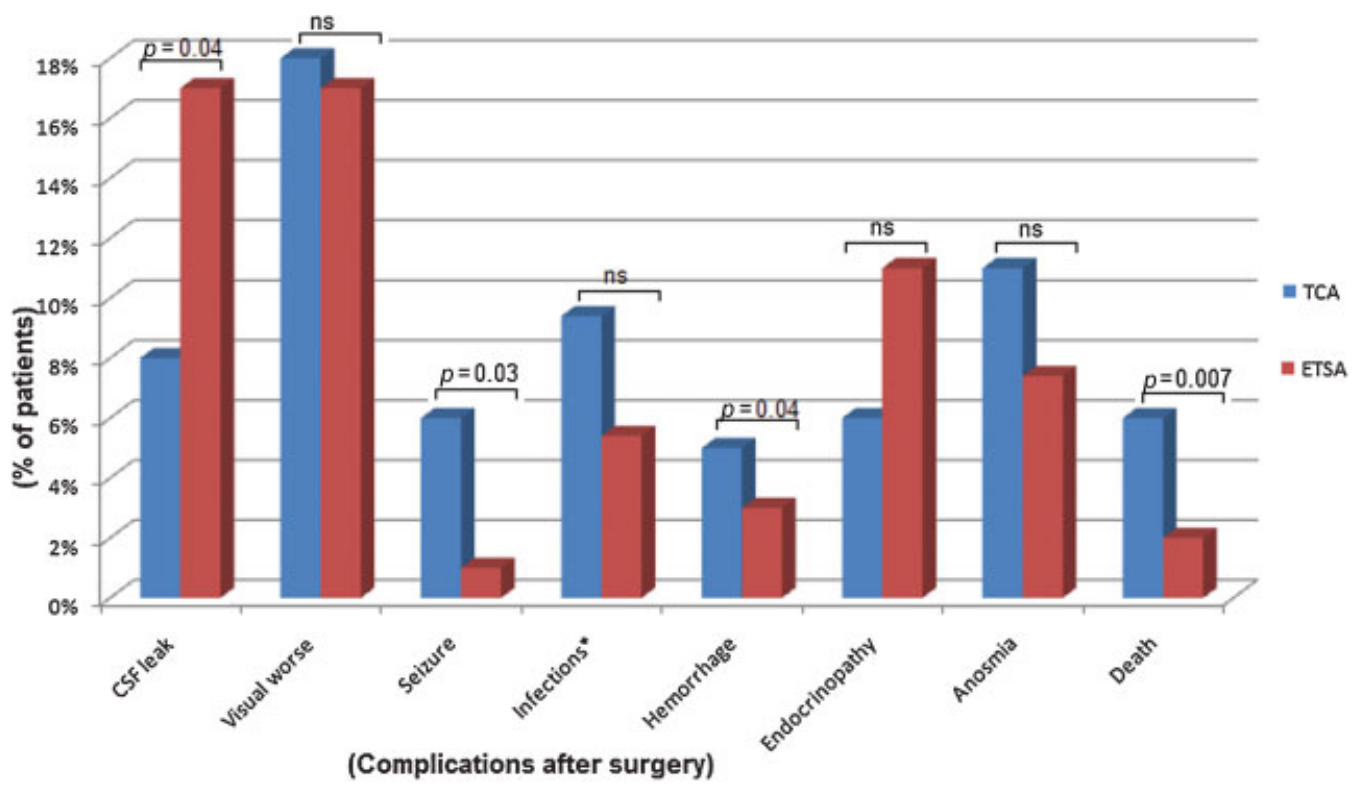

Fig. 6 Perioperative complications following transcranial and endoscopic transsphenoidal approach for midline suprasellar meningioma resection.

cosmetic results. ${ }^{51}$ This approach also shortens the recovery time, lessens injury to brain parenchyma (no brain retraction), ${ }^{19}$ provides clear vision between the internal carotid artery (ICA) to ICA and easy removal of sellar extension tumors. Moreover, it has also been the choice of surgery in elderly patients or patients with major comorbidities that cannot stand surgery. ${ }^{21,52}$ However, ETSA has been limited in number of cases due to increased risk of CSF leakage/CSF fistulae ${ }^{19,52}$ and inadequate removal due to the nature of tumor (hard/calcified/large/above optic nerve/ more laterally located). ${ }^{19}$

\section{Surgical Outcomes}

The reports of the present study relate favorably with those of other studies. ${ }^{19,20,78,79}$ For example, Komotar et al observed significantly higher rate of GTR in endoscopic group compared with transcranial group ( 92.8 vs $63.2 \% ; p<0.001) .{ }^{79}$ Removal of the tumor as much as possible is the ultimate goal of resection in neurosurgery. Nonetheless, several studies have highlighted the fact that complete resection at the cost of visual deterioration or hypothalamic dysfunction should not be attempted. With the advent of modern microsurgery, the amount of GTR rate has leaped from 35 to $76 \%$ (macrosurgical era) to 58 to $100 \%$ (of the microsurgical era). ${ }^{25}$ Resection of MSM is a complex procedure and depends on various factors like size of meningioma, arterial encasement, peritumoral edema, and approaches followed. ${ }^{34}$ Whatever the influential factor may be, the extent of resection is paramount in predicting subsequent recurrence. Studies conducted earlier have reported the yield of GTR during TCA to be 70 to $100 \%$ while that with ETSA to be between 50 to $84 \%{ }^{20,63}$ Contrarily, studies conducted by de Divitiis et al ${ }^{19}$ have revealed $83.3 \%$ GTR during TCA while $86.4 \%$ GTR yield during ETSA. Our findings too followed the latter pattern with $80 \%$ GTR during TCA and $83 \%$ GTR during ETSA, with no statistical association $(p=0.43)$.
One of the undesired results of MSM surgery is tumor recurrence which is influenced by varieties of factors. As outlined by Fahlbusch and Schott, ${ }^{13}$ these factors can be: 1) extent of tumor resection, 2) histological grading of the tumor, 3) length of follow-up period, and 4) mode and quality of assessment of tumor recurrence. TSA approach being less invasive with a shorter hospital stay, the compliance to longterm follow-up becomes questionable. Most of the previously conducted ETSA studies have had 6 to 24 months of followups (mean, $21 \pm 18$ months) ${ }^{51}$ while the mean follow-up duration for TCA was 51.8 months (0.8-112 months). ${ }^{79}$ Recurrence rate for MSM ranges from $5 \%$ to $>30 \%$ and the rate increases with longer follow-ups. ${ }^{1-3,10,12,80}$ Our observations, as shown in - Table 3 , too shared the same fact as seen by lack of $100 \%$ follow-up rates with both the procedures, (TCA, 73.3\% vs ETSA, 79\%). Moreover, the length of mean follow-up period for TCA was longer as compared with ETSA (53 vs 19 months) and the $p$-value approaching 0.002 . As a result, the recurrence rate with TCA was higher as compared with ETSA ( 7 vs $5 \% ; p=0.02$ ). Meningiomas, although histologically benign, can recur and progress over time, so longer follow-up is necessary to evaluate the longterm outcome.

As mentioned earlier, good visual outcome is the target of a successful MSM surgery. In relation to the surgical approach undertaken, recent meta-analysis have demonstrated more visual improvements with ETSA (75\%) as compared with TCA (58.4\%), although the observations did not have statistical significance. ${ }^{19}$ Our studies also demonstrated almost similar rate of visual improvement with no statistically significant difference (TCA vs ETSA, 71 vs $70 \% ; p=0.26$ )), as depicted in - Table 4. Moreover, some series have identified ETSA to deliver higher visual functional improvement in comparison to TCA. ${ }^{22,49,69,79,81}$ Our observations, however, also demonstrated higher rate of visual worsening with TCA 
than with ETSA and no statistical association (18 vs $15 \%$; $p=0.12$ ). This lower rate of visual worsening encountered with the ETSA approach was attributed to minimal manipulation of compromised ischemic optic apparatus, adequate and early visualization of the subchiasmatic blood vessels, and precision and safer handling of the optic apparatus. $^{51}$

\section{Operative Complications}

On the other hand, we observed that both TCA and ETSA did not differ significantly in visual improvement and GTR but postoperative complications, specifically, seizure and hemorrhage was significantly predominant in TCA as compared with ETSA. ${ }^{19,78}$ Some series reported that surgical morbidities such as seizure and hemorrhage were lower in patients treated with ETSA as compared with TCA. Symon and Rosenstein also reported that new onset seizure was a commonly occurring complication of MSM surgery being as high as in $10.9 \%$ of cases during TCA. ${ }^{82}$ Our study also revealed cases of new onset seizure and the prevalence being more (6\%) with TCA than with ETSA (1\%). Similarly, intracerebral hemorrhage was found to be more with TCA than ETSA (5 vs 3\%). Observation of low cases of seizure and hemorrhage in ETSA in comparison to TCA is expected because in TCA, more or less frontal lobe retraction needs to be done which may cause rupture of small feeding blood vessels and injury to brain parenchyma causing seizure. But ETSA has been superior to TCA in the field of early devascularization of main feeding vessels and no brain retraction. $^{19}$ Theoretically, postoperative CSF leakage is a potential complication of approaches and occurs via the frontal sinus during TCA. But in practice and in numerous researches namely, Komotar et $\mathrm{al}^{79}$ ( 21.3 vs $4.3 \%$; $p<0.001$ ), ETSA is found to be associated with higher rates of CSF leakage than with the TCA. ${ }^{19,20,63,83}$ Our study has also shown that postoperative CSF leakage occurs more with ETSA than with TCA (17 vs $8 \% ; p=0.04$ ) (-Table 4).

Finally, we report that TCA and ETSA surgical approaches for MSM removal do not display complete superiority over each other when assessed on the basis of postoperative outcome measures. This was apparent since TCA and ETSA displayed poor outcomes with regard to recurrence rates and CSF leakage respectively, coincidentally, two of the commonly used postoperation determinants of improvement. Generally, it was observed that both TCA and ETSA did not improve worsening of visual function, visual improvement, and GTR. However, reduced CSF leakage and increased recurrence rate was associated with TCA, while reduced recurrent rate and increased CSF leakage was attributable to ETSA. The poor recurrence rate associated with TCA may be linked to the long follow-up period, while the comparatively reduced recurrence rate in ETSA cohorts may be accounted for by the short followup period. It was apparent that patients who underwent MSM removal by both TCA and ETSA have almost similar preoperative clinical characteristics, an observation which strengthens the comparability of the two cohorts. The results of this review are not much different from recent studies, which have shown that none of the surgical approaches could be seen as an end in itself since both have advantages and disadvantages, thus the choice of TCA or ETSA may be determined by tumor characteristics, patient-specific clinical presentations, risk/benefits, and prioritization of clinical objectives.

\section{Limitations}

This study, among other factors, may be limited by case heterogeneity, methodological heterogeneity which cannot be cured completely by statistical method, because the study is retrospective in nature. For instance, length of follow-up and tumor characteristics for both cohorts in some cases differed.

\section{Conclusions}

Put together, the choice of TCA or ETSA for surgical removal of MSMs may depend on many factors including tumor characteristics, patient-specific clinical presentations, risk/ benefit assessment, and the clinical objective. Ideally, a surgical approach that can maximize the advantages of both TCA and ETSA while at the same time minimize the risks associated with these approaches must be sought.

\section{Conflict of Interest}

None.

\section{Funding}

None.

\section{Acknowledgments}

We would like to thank Dr. Dejun Wu, Dr. Jian Tao, and Dr. Li Dekun at the Department of Neurosurgery, Anhui Medical University for their valuable guidance and revision of our illustrations.

\section{References}

1 Al-Mefty O, Smith R. Tuberculum sellae meningiomas. Meningiomas Raven, New York 1991;395411:395-411

2 Al-Mefty O, Holoubi A, Rifai A, Fox JL. Microsurgical removal of suprasellar meningiomas. Neurosurgery 1985;16(3):364-372

3 Brihaye J, Brihaye-van Geertruyden M. Management and surgical outcome of suprasellar meningiomas. Proceedings of the 8th European Congress of Neurosurgery Barcelona, September 6-11, 1987: Springer; 1988:124-129

4 Arifin MZ, Mardjono I, Sidabutar R, Wirjomartani BA, Faried A. Pterional approach versus unilateral frontal approach on tuberculum sellae meningioma: single centre experiences. Asian J Neurosurg 2012;7(1):21-24

5 Chi JH, McDermott MW. Tuberculum sellae meningiomas. Neurosurg Focus 2003;14(6):e6

6 Ciric I, Rosenblatt S. Suprasellar meningiomas. Neurosurgery 2001;49(6):1372-1377

7 Goel A, Muzumdar D, Desai KI. Tuberculum sellae meningioma: a report on management on the basis of a surgical experience with 70 patients. Neurosurgery 2002;51(6):1358-1363, discussion 1363-1364 
8 Ganna A, Dehdashti AR, Karabatsou K, Gentili F. Fronto-basal interhemispheric approach for tuberculum sellae meningiomas; long-term visual outcome. Br J Neurosurg 2009;23(4):422-430

9 Galal A, Faisal A, Al-Werdany M, El Shehaby A, Lotfy T, Moharram $\mathrm{H}$. Determinants of postoperative visual recovery in suprasellar meningiomas. Acta Neurochir (Wien) 2010;152(1):69-77

10 Mirimanoff RO, Dosoretz DE, Linggood RM, Ojemann RG, Martuza RL. Meningioma: analysis of recurrence and progression following neurosurgical resection. J Neurosurg 1985;62(1):18-24

11 Nanda A, Ambekar S, Javalkar V, Sharma M. Technical nuances in the management of tuberculum sellae and diaphragma sellae meningiomas. Neurosurg Focus 2013;35(6):E7

12 Andrews BT, Wilson CB. Suprasellar meningiomas: the effect of tumor location on postoperative visual outcome. J Neurosurg 1988;69(4):523-528

13 Fahlbusch R, Schott W. Pterional surgery of meningiomas of the tuberculum sellae and planum sphenoidale: surgical results with special consideration of ophthalmological and endocrinological outcomes. J Neurosurg 2002;96(2):235-243

14 Jallo GI, Benjamin V. Tuberculum sellae meningiomas: microsurgical anatomy and surgical technique. Neurosurgery 2002;51(6):1432-1439, discussion 1439-1440

15 Schick U, Hassler W. Surgical management of tuberculum sellae meningiomas: involvement of the optic canal and visual outcome. J Neurol Neurosurg Psychiatry 2005;76(7):977-983

16 Zevgaridis D, Medele RJ, Müller A, Hischa AC, Steiger H-J. Meningiomas of the sellar region presenting with visual impairment: impact of various prognostic factors on surgical outcome in 62 patients. Acta Neurochir (Wien) 2001;143(5): 471-476

17 Kaptain GJ, Vincent DA, Sheehan JP, Laws ER Jr. Transsphenoidal approaches for the extracapsular resection of midline suprasellar and anterior cranial base lesions. Neurosurgery 2001;49(1): 94-100, discussion 100-101

18 Park C-K, Jung H-W, Yang S-Y, Seol HJ, Paek SH, Kim DG. Surgically treated tuberculum sellae and diaphragm sellae meningiomas: the importance of short-term visual outcome. Neurosurgery 2006;59(2):238-243, discussion 238-243

19 de Divitiis E, Esposito F, Cappabianca P, Cavallo LM, de Divitiis O. Tuberculum sellae meningiomas: high route or low route? A series of 51 consecutive cases. Neurosurgery 2008;62(3): 556-563, discussion 556-563

20 Fatemi N, Dusick JR, de Paiva Neto MA, Malkasian D, Kelly DF. Endonasal versus supraorbital keyhole removal of craniopharyngiomas and tuberculum sellae meningiomas. Neurosurgery 2009;64(5, Suppl 2):269-284, discussion 284-286

21 Kitano M, Taneda M, Nakao Y. Postoperative improvement in visual function in patients with tuberculum sellae meningiomas: results of the extended transsphenoidal and transcranial approaches. J Neurosurg 2007;107(2):337-346

22 Van Gompel JJ, Frank G, Pasquini E, Zoli M, Hoover J, Lanzino G. Expanded endonasal endoscopic resection of anterior fossa meningiomas: report of 13 cases and meta-analysis of the literature. Neurosurg Focus 2011;30(5):E15

23 Bassiouni H, Asgari S, Stolke D. Tuberculum sellae meningiomas: functional outcome in a consecutive series treated microsurgically. Surg Neurol 2006;66(1):37-44, discussion 44-45

24 Liu Y, Chotai S, Ming C, Jin S, Pan J, Qi S. Characteristics of midline suprasellar meningiomas based on their origin and growth pattern. Clin Neurol Neurosurg 2014;125:173-181

25 Nakamura M, Roser F, Struck M, Vorkapic P, Samii M. Tuberculum sellae meningiomas: clinical outcome considering different surgical approaches. Neurosurgery 2006;59(5):1019-1028, discussion 1028-1029

26 Arai H, Sato K, Okuda O, et al. Transcranial transsphenoidal approach for tuberculum sellae meningiomas. Acta Neurochir (Wien) 2000;142(7):751-756, discussion 756-757
27 Kim T-W, Jung S, Jung T-Y, Kim I-Y, Kang S-S, Kim S-H. Prognostic factors of postoperative visual outcomes in tuberculum sellae meningioma. Br J Neurosurg 2008;22(2):231-234

28 Landeiro JA, Gonçalves MB, Guimarães RD, et al. Tuberculum sellae meningiomas: surgical considerations. Arq Neuropsiquiatr 2010;68(3):424-429

29 Pamir MN, Özduman K, Belirgen M, Kilic T, Özek MM. Outcome determinants of pterional surgery for tuberculum sellae meningiomas. Acta Neurochir (Wien) 2005;147(11):1121-1130, discussion 1130

30 Sade B, Lee JH. High incidence of optic canal involvement in tuberculum sellae meningiomas: rationale for aggressive skull base approach. Surg Neurol 2009;72(2):118-123, discussion 123

31 Nozaki K, Kikuta K, Takagi Y, Mineharu Y, Takahashi JA, Hashimoto N. Effect of early optic canal unroofing on the outcome of visual functions in surgery for meningiomas of the tuberculum sellae and planum sphenoidale. Neurosurgery 2008; 62(4):839-844, discussion 844-846

32 Ohta K, Yasuo K, Morikawa M, Nagashima T, Tamaki N. Treatment of tuberculum sellae meningiomas:a long-term follow-up study. J Clin Neurosci 2001;8(Suppl 1):26-31

33 Mathiesen T, Kihlström L. Visual outcome of tuberculum sellae meningiomas after extradural optic nerve decompression. Neurosurgery 2006;59(3):570-576, discussion 570-576

34 Palani A, Panigrahi MK, Purohit AK. Tuberculum sellae meningiomas: a series of 41 cases; surgical and ophthalmological outcomes with proposal of a new prognostic scoring system. J Neurosci Rural Pract 2012;3(3):286-293

35 Li X, Liu M, Liu Y, Zhu S. Surgical management of tuberculum sellae meningiomas. J Clin Neurosci 2007;14(12):1150-1154

36 Otani N, Muroi C, Yano H, Khan N, Pangalu A, Yonekawa Y. Surgical management of tuberculum sellae meningioma: role of selective extradural anterior clinoidectomy. Br J Neurosurg 2006; 20(3):129-138

37 Jang W-Y, Jung S, Jung T-Y, Moon K-S, Kim I-Y. The contralateral subfrontal approach can simplify surgery and provide favorable visual outcome in tuberculum sellae meningiomas. Neurosurg Rev 2012;35(4):601-607, discussion 607-608

38 Mehrazin M, Mirfalah R. Early postoperative visual outcome in microsurgically treated suprasellar meningiomas predict longterm visual outcome. Turk Neurosurg 2008;18(4):380-386

39 Seol HJ, Park H-Y, Nam D-H, et al. Clinical outcomes of tuberculum sellae meningiomas focusing on reversibility of postoperative visual function. Acta Neurochir (Wien) 2013; 155(1):25-31

40 Lu ZF, Cheng XB, Zhao YG, Shi BZ. Twenty-nine cases of resection of suprasellar meningioma through small bone window: an interhemispheric approach. Contemp Oncol (Pozn) 2013;17(6): 525-529

41 Ceylan S, Koc K, Anık I. Extended endoscopic transsphenoidal approach for tuberculum sellae meningiomas. Acta Neurochir (Wien) 2011;153(1):1-9

42 Chowdhury FH, Haque MR, Goel AH, Kawsar KA. Endoscopic endonasal extended transsphenoidal removal of tuberculum sellae meningioma (TSM): an experience of six cases. $\mathrm{Br} \mathrm{J}$ Neurosurg 2012;26(5):692-699

43 Gadgil N, Thomas JG, Takashima M, Yoshor D. Endoscopic resection of tuberculum sellae meningiomas. J Neurol Surg B Skull Base 2013;74(4):201-210

44 Koutourousiou M, Fernandez-Miranda JC, Stefko ST, Wang EW, Snyderman $\mathrm{CH}$, Gardner PA. Endoscopic endonasal surgery for suprasellar meningiomas: experience with 75 patients. J Neurosurg 2014;120(6):1326-1339

45 Ogawa Y, Tominaga T. Extended transsphenoidal approach for tuberculum sellae meningioma-what are the optimum and critical indications? Acta Neurochir (Wien) 2012;154(4):621-626 
46 Khan OH, Krischek B, Holliman D, et al. Pure endoscopic expanded endonasal approach for olfactory groove and tuberculum sellae meningiomas. J Clin Neurosci 2014;21(6):927-933

47 Laufer I, Anand VK, Schwartz TH. Endoscopic, endonasal extended transsphenoidal, transplanum transtuberculum approach for resection of suprasellar lesions. J Neurosurg 2007; 106(3):400-406

48 Gardner PA, Kassam AB, Thomas A, et al. Endoscopic endonasal resection of anterior cranial base meningiomas. Neurosurgery 2008;63(1):36-52, discussion 52-54

49 Attia M, Kandasamy J, Jakimovski D, et al. The importance and timing of optic canal exploration and decompression during endoscopic endonasal resection of tuberculum sella and planum sphenoidale meningiomas. Neurosurgery 2012;71(1, Suppl Operative):58-67

50 Bohman L-E, Stein SC, Newman JG, et al. Endoscopic versus open resection of tuberculum sellae meningiomas: a decision analysis. ORL J Otorhinolaryngol Relat Spec 2012;74(5):255-263

51 Wang Q, Lu X-J, Ji W-Y, et al. Visual outcome after extended endoscopic endonasal transsphenoidal surgery for tuberculum sellae meningiomas. World Neurosurg 2010;73(6): 694-700

52 Couldwell WT, Weiss MH, Rabb C, Liu JK, Apfelbaum RI, Fukushima T. Variations on the standard transsphenoidal approach to the sellar region, with emphasis on the extended approaches and parasellar approaches: surgical experience in 105 cases. Neurosurgery 2004;55(3):539-547, discussion 547-550

53 DerSimonian R. Combining evidence from clinical trials. Anesth Analg 1990;70(5):475-476

54 DerSimonian R, Charette LJ, McPeek B, Mosteller F. Reporting on methods in clinical trials. N Engl J Med 1982;306(22):1332-1337

55 DerSimonian R, Laird N. Meta-analysis in clinical trials. Control Clin Trials 1986;7(3):177-188

56 DerSimonian R. Meta-analysis in the design and monitoring of clinical trials. Stat Med 1996;15(12):1237-1248, discussion 1249-1252

57 Stirling J, Edin M. Tumor of the meninges in the region of the pituitary body, pressing on the chiasma. Ann Ophthalmol 1897; 6:15-16

58 Cushing H, Eisenhardt L. Suprasellar meningiomas. Meningiomas: Their Classification, Regional Behaviour, Life History, and Surgical End Results. UK. Hafner Publishing Co Ltd; 1938:224-49

59 Benjamin V, Russell SM. The microsurgical nuances of resecting tuberculum sellae meningiomas. Neurosurgery 2005;56(2, Suppl):411-417, discussion

60 Noguchi A, Balasingam V, McMenomey SO, Delashaw JB Jr. Supraorbital craniotomy for parasellar lesions. Technical note. J Neurosurg 2005;102(5):951-955

61 Schmidt RF, Choudhry OJ, Takkellapati R, Eloy JA, Couldwell WT Liu JK. Hermann Schloffer and the origin of transsphenoidal pituitary surgery. Neurosurg Focus 2012;33(2):E5

62 Dusick JR, Esposito F, Kelly DF, et al. The extended direct endonasal transsphenoidal approach for nonadenomatous suprasellar tumors. J Neurosurg 2005;102(5):832-841

63 Cook SW, Smith Z, Kelly DF. Endonasal transsphenoidal removal of tuberculum sellae meningiomas: technical note. Neurosurgery 2004;55(1):239-244, discussion 244-246

64 Kassam AB, Thomas A, Carrau RL, et al. Endoscopic reconstruction of the cranial base using a pedicled nasoseptal flap. Neurosurgery 2008;63(1, Suppl 1):ONS44-ONS52, discussion ONS52-ONS53

65 Kouri JG, Chen MY, Watson JC, Oldfield EH. Resection of suprasellar tumors by using a modified transsphenoidal approach. Report of four cases. J Neurosurg 2000;92(6):1028-1035
66 Maira G, Anile C, Albanese A, Cabezas D, Pardi F, Vignati A. The role of transsphenoidal surgery in the treatment of craniopharyngiomas. J Neurosurg 2004;100(3):445-451

67 Honegger J, Fahlbusch R, Buchfelder M, Huk WJ, Thierauf P. The role of transsphenoidal microsurgery in the management of sellar and parasellar meningioma. Surg Neurol 1993;39(1):18-24

68 Fatemi N, Dusick JR, de Paiva Neto MA, Kelly DF. The endonasal microscopic approach for pituitary adenomas and other parasellar tumors: a 10-year experience. Neurosurgery 2008; 63(4, Suppl 2):244-256, discussion 256

69 Cappabianca P, Cavallo L, Esposito F, De Divitiis O, Messina A, De Divitiis E. Extended endoscopic endonasal approach to the midline skull base: the evolving role of transsphenoidal surgery. Adv Tech Stand Neurosurg 2008;33:151-199

70 de Divitiis E, Cavallo LM, Esposito F, Stella L, Messina A. Extended endoscopic transsphenoidal approach for tuberculum sellae meningiomas. Neurosurgery 2007;61(5, Suppl 2):229-237, discussion 237-238

71 Liu JK, Christiano LD, Patel SK, Tubbs RS, Eloy JA. Surgical nuances for removal of tuberculum sellae meningiomas with optic canal involvement using the endoscopic endonasal extended transsphenoidal transplanum transtuberculum approach. Neurosurg Focus 2011;30(5):E2

72 Bowers CA, Altay T, Couldwell WT. Surgical decision-making strategies in tuberculum sellae meningioma resection. Neurosurg Focus 2011;30(5):E1

73 Ceylan S, Koc K, Anik I. Extended endoscopic approaches for midline skull-base lesions. Neurosurg Rev 2009;32(3):309-319, discussion 318-319

74 Chokyu I, Goto T, Ishibashi K, Nagata T, Ohata K. Bilateral subfrontal approach for tuberculum sellae meningiomas in long-term postoperative visual outcome. J Neurosurg 2011;115(4):802-810

75 Mahmoud M, Nader R, Al-Mefty O. Optic canal involvement in tuberculum sellae meningiomas: influence on approach, recurrence, and visual recovery. Neurosurgery 2010;67(3, Suppl Operative ):ons108-ons118, discussion ons118-ons119

76 Hadad G, Bassagasteguy L, Carrau RL, et al. A novel reconstructive technique after endoscopic expanded endonasal approaches: vascular pedicle nasoseptal flap. Laryngoscope 2006;116(10):1882-1886

77 Zanation AM, Carrau RL, Snyderman CH, et al. Nasoseptal flap reconstruction of high flow intraoperative cerebral spinal fluid leaks during endoscopic skull base surgery. Am J Rhinol Allergy 2009;23(5):518-521

78 Clark AJ, Jahangiri A, Garcia RM, et al. Endoscopic surgery for tuberculum sellae meningiomas: a systematic review and metaanalysis. Neurosurg Rev 2013;36(3):349-359

79 Komotar RJ, Starke RM, Raper DM, Anand VK, Schwartz TH. Endoscopic endonasal versus open transcranial resection of anterior midline skull base meningiomas. World Neurosurg 2012;77(5-6):713-724

80 Rosenstein J, Symon L. Surgical management of suprasellar meningioma. Part 2: Prognosis for visual function following craniotomy. J Neurosurg 1984;61(4):642-648

81 Dehdashti AR, Ganna A, Witterick I, Gentili F. Expanded endoscopic endonasal approach for anterior cranial base and suprasellar lesions: indications and limitations. Neurosurgery 2009;64(4):677-687, discussion 687-689

82 Symon L, Rosenstein J. Surgical management of suprasellar meningioma. Part 1: The influence of tumor size, duration of symptoms, and microsurgery on surgical outcome in 101 consecutive cases. J Neurosurg 1984;61(4):633-641

83 Wang Q Lu XJ, Li B, Ji WY, Chen KL. Extended endoscopic endonasal transsphenoidal removal of tuberculum sellae meningiomas: a preliminary report. J Clin Neurosci 2009;16(7):889-893 